Errata

\title{
Results of exploratory coring in Iaguna Lake, Philippines
}

P. G. Sly ${ }^{1}$, M. N. Charlton ${ }^{2}$ \& S. R. Joshi ${ }^{2}$

${ }^{1}$ Rawson Academy of Aquatic Science, Suite 404, 1 Nicholas Street, Ottawa, Ontario, K1N $7 B 7$, Canada: ${ }^{2}$ National Water Research Institute, CCIW. P.O. Box 5050, Burlington. Ontario, L7R $4 A 6$. Canada

Hydrobiologia 257: 153-164, 1993.

In the above article, Fig. 4 was unfortunately omitted from the final printed version. In its place on p. 159 appears a duplicated Fig. 3 above the correct legend for Fig. 4. We now present the correct Fig. 4 below.

The first equation and following text on p. 158 should read as follows:

$$
\mathrm{C}(x)=\mathrm{C}(0) \cdot \exp (-\lambda x / S)
$$

where $\lambda$ is subsequently defined as the decay constant of ${ }^{210} \mathrm{~Pb}(0.0311 y)$

We apologize for any inconvenience caused to the reader.

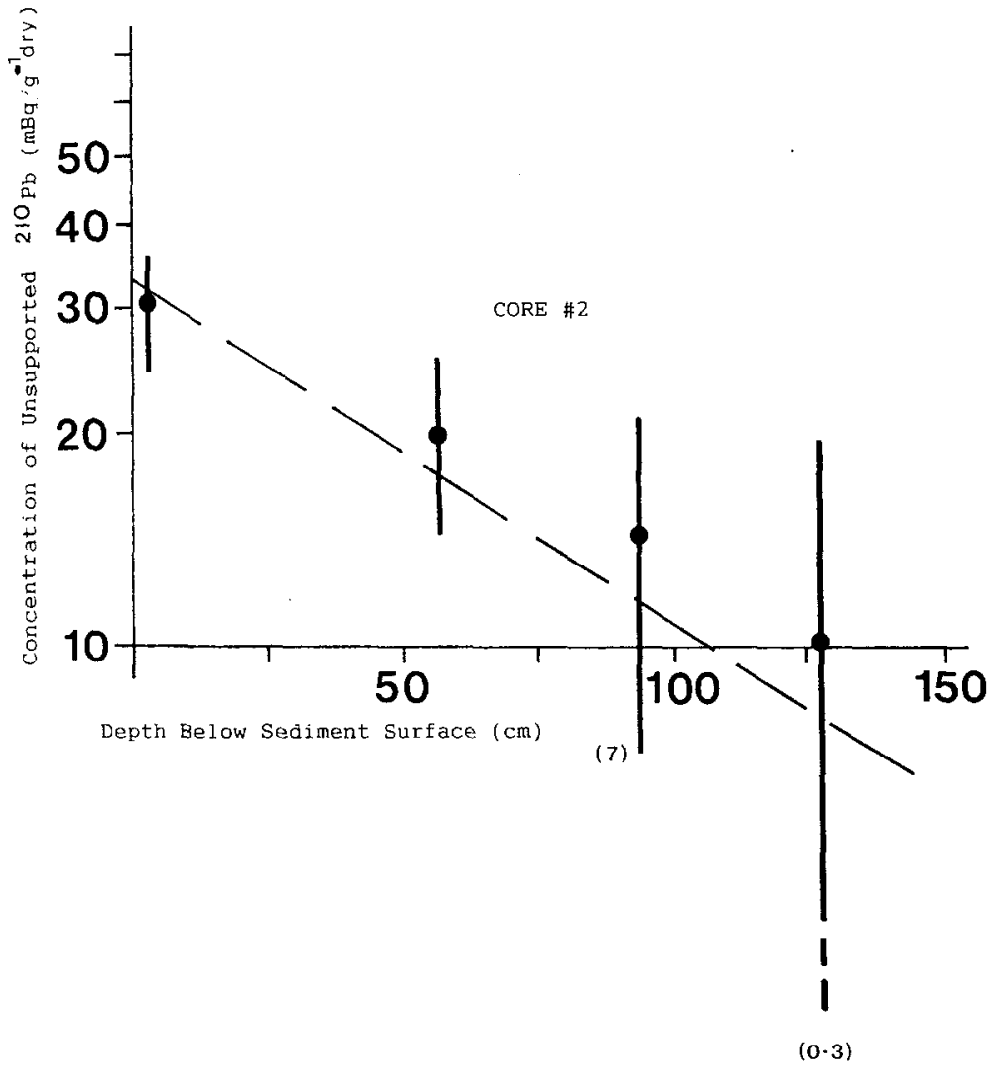

Fig. 4. Core \# 2, Unsupported ${ }^{210} \mathrm{~Pb}$ vs. Sediment depth. 